\title{
ASSESSMENT OF COPING STRATEGIES AND PSYCHOLOGICAL ADJUSTMENT IN CHILDREN
}

\author{
Francisco Manuel Morales Rodríguez \\ University of Malaga, Malaga, Spain \\ E-mail: framorrod@uma.es
}

\begin{abstract}
The study of coping strategies in children and adolescents is a topic in line with the study of a healthy development, as the very fact of having coping skills serves as a guarantee for a healthy lifestyle and quality of life. The general aim is the prediction of children coping (coping strategies used by students of elementary education, and in relation to four types of stressors known as the school, family, peer interaction and health) in terms of the impact of varying stress, coping, School, clinical and social maladjustment. Participants were 402 students, ranging from 9 to 12 years old. Results show that that the variable coping with the ACS, stress and clinical maladjustment predict, with different impact, coping strategy employed by children. This information attempts to be useful in the applied Educational.
\end{abstract}

Key words: assessment, coping strategies, maladjustment, middle-childhood.

\section{Introduction}

The coping strategies employed by children and adolescents can have an impact on their development and psychological well-being, given that having positive coping skills is a guarantee for a healthy lifestyle and quality of life (Folkman \& Moskowitz, 2004; Urzua \& Jarne, 2008). Additionally, the dysfunctional coping response to stress can have negative and adverse effects on children's and adolescents' development (Seiffge-Krenke, 2000; Seiffge-Krenke \& Klessinger, 2000). Therefore, the assessment of positive coping, together with its differentiation from unproductive coping, needs to be considered when planning for psycho-educational intervention, which aims to promote a healthy development in children and adolescents. Such measures should demonstrate both validity and reliability to assess, not only the constructive coping - in order to promote it - but also the unproductive one - in order to prevent and avoid it - (Compas, Connor-Smith, Saltzman, Thomsen, \& Wadsworth, 2001; Hampel \& Petermann, 2006; Penley, Tomaka, \& Wiebe, 2002). Questionnaires are often used to assess children and adolescents, in particular self-reported questionnaires, as they allow for the collection of subjective responses, which are closely related to behaviour and cognition.

The general tendency until the end of the 1970's involved the assessment of general coping behaviour by way of general strategies to be used in different situations. However, a current approach was adopted in the assessment of coping strategies, based on the model developed by Lazarus and Folkman (1984). This approach considered coping strategies as the result of a process depending on specific situations and on the individual assessment of these situations. Thus, the current approach focuses on the assessment of a situation-specific coping strategy, given that the efficacy of the coping 
68 strategy in each case will depend on contextual or situational factors related to the specific type of stressor (Ayers, Sandler, West, \& Roosa, 1996; Claes, Witteman, \& Van den Bercken, 2009; Stern $\&$ Zevron, 1990). This view allows for certain criticisms of measurements that are already present in the current market. In their review, Compas et al. (2001) point out that some of the existing measurements do not follow a situational approach. For instance, Kidcope (Spirito, Stark, Gil, \& Tyc, 1995) offers the reader a list of strategies that can be applied to all presented situations regardless of their content.

The same literature review (Compas et al., 2001 Connor-Smith, Compas, Wadsworth, Thomsen, \& Saltzman, 2000; Krane \& Slaney, 2005; Sandin, 2003; Santed, Sandin, Chorot, \& Olmedo, 2000, 2001; Seiffge-Krenke, 2000; Spirito, Stark, \& Williams, 1988; Tein, Sandler, \& Zautra, 2000) shows that coping strategies used by children and adolescents relate variables such as the stress and the adjustment/e inadequacy, which can help to predict the behaviour of coping. We compare the extent to which the coping strategies evaluated by an instrument are consistent with the evaluated by another which examines such factors, as well as also we analyze the impact on the coping with the stress and psychological adjustment as predictive variables.

\section{Problem of Research}

That types of strategies can have very different results depending on their impact on child development is necessary to assess accurately both the measurement of child coping compared to that obtained in another measure to assess coping as well as what are its relations with other variables such as stress or the degree of psychological adjustment (Salkovskis \& Campbell, 1994). This study aims to analyze the relationships between the variable stress, coping and maladjustment.

\section{Methodology of Research}

\section{General Background of Research}

This study was funded by the Dirección General de Investigación (General Research Design, Spanish Ministry of Education and Science). (Ref. SEJ2007-61447) (2007-2010). The present study aims to analyze the extent to which the coping strategies evaluated by an instrument are consistent with the evaluated by another which examines such factors, as well as also the present study aims to analyze the impact on the coping with the stress and psychological adjustment as predictive variables.

\section{Sample of Research}

Participants were 402 children, 190 girls and 212 boys ranging in age from 9 to 12 years old, with an average age of $10.49(S D=1.00)$, and who attended two public schools and two state-subsidised schools. A non-probability-based incidental sample was used. The sample is gender-balanced and most participants are between ten and eleven years old, that is, in their late childhood or early adolescence. Schools are located in urban areas with families of middle socioeconomic status.

\section{Instrument and Procedures}

Situational Coping Strategies Inventory in Children (ESAN). This self-reporting instrument examines coping strategies which have arisen from four daily common problems related to family, health, peer interaction and school. These strategies were empirically extracted from a previous study based on a sample of 966 individuals, whose responses to open problems were analysed by two observers. The result of such analysis was an adequate inter-rater reliability $(r=0.67)$; and the responses were categorised into ten different coping strategies, which account for the content of the ten items attached to each of the four hypothetical problems. The final version of the ESAN consists of 40 items, equitably distributed into 4 problem-situations, with a response 
format organised in 5 steps. The response refers to the last 12 months. Each problem offers the possibility of delivering an open response in which a strategy not found among the suggested ones may be described.

Adolescent Coping Scale (ACS; Frydenberg \& Lewis, 1993). This instrument assesses coping in children and adolescents and presents a Spanish adaptation (Gomez-Fraguela, Luengo, Romero, Villar, \& Sobral, 2006). This study has applied the short version of the adapted scale; including 18 items and the content refers to a total of 18 strategies frequently used by the individual to deal with certain worries, difficulties or problems. The score scale introduces five points; from 1. It never happens to me or I never do it to 5. It happens to me or I do it very often. Such coping strategies are considered to be consistent $(\alpha=0.75)$ regardless of the nature of the problem. This scale presents an acceptable test-retest reliability coefficient $(r=0.68)$. The factorial analysis of such strategies throws up three factors which identify with three basic coping styles (Frydenberg \& Lewis, 1996): 1. Focused on the problem, which consists of five sub-scales: focusing on solving the problem, seeking for relaxing entertainment, physical recreation, working hard and achieving, and focus on the positive; 2. Coping in relation to others, which consists of six sub-scales: seeking for social support, seeking for professional support, seeking for spiritual support, seeking to belong, social action, and investing in close friends; and 3. Unproductive coping, which consists of seven sub-scales: worrying, wishful thinking, not coping, ignoring the problem, keeping to self, self-blame and tension reduction. The internal consistency for each of the factors in this sample is as follows: $\alpha=0.53$ for problem-specific coping scale, $\alpha=0.51$ for in relation to others, and $\alpha=0.53$ for unproductive coping.

Children 's Daily Stress Inventory (IIEC; Trianes et al., 2009). The IIEC consists of 25 dichotomous items filled in by each student, which allows for the assessment of perceived daily stress in situations referred to in three main fields: health (12 items), peer interaction and school (6 items) and family ( 7 items). Additionally, this instrument allows for a general score to be collected based on self-reports and presents adequate psychometric properties. The total IIEC score in this sample shows an internal consistency of $\alpha=0.70$.

Behaviour Assessment System for Children (BASC; Reynolds \& Kamphaus, 1992). This study has used the Spanish version introduced by Gonzalez, Fernandez, Perez, and Santamaria (2004). More specifically, it has used a particular BASC component: the Self-Report of Personality (S2) for children with ages ranging from 8 to 12 . The measure is composed of 146 statements to be answered as true or false. It consists of twelve scales, grouped in eight clinical scales and four adjustment scales. The BASC reports four general scales or composite indexes that account for frequently used variables in the research field of psychopathology and maladaptation (Keane \& Calkins, 2004); and which are as follows: school maladjustment, clinical maladjustment, personal adjustment, and emotional symptoms. The general score of each one of these scales was used. The internal consistency for each scale in this sample was as follows: $\alpha=0.85$ for school maladjustment, $\alpha=0.90$ for clinical maladjustment, $\alpha=0.84$ for personal adjustment, and $\alpha=0.93$ for emotional symptoms.

Schools were contacted and informed of the study objectives. Likewise, parents were asked for their written permission and consent for the research, and provided with the relevant instructions and informative notes. Students were informed of the voluntary nature of their participation and data confidentiality was guaranteed. The administration of the tests was carried out by two researchers who were trained to explain the objectives to teachers as well as to give the appropriate instructions to students. Questionnaires were collectively filled out during school hours. The order in which the tests were administered was as follows: the IIEC, ACS and ESAN were administered in a first session (1 hour), whereas the BASC was administered in a second session (1 hour). Statistical analyses were conducted using the statistical software package SPSS 15.0.

\section{Data Analysis}

Linear regression analyses were carried out with the purpose of considering the best possible ESAN coping predictive model based on the impact of the ACS coping variables, the IIEC stress variable and the BASC school, social and clinical maladjustment variables (independent variables). 
OF PSYCHOLOGY IN THE $21^{\text {st }}$ CENTURY Volume 3, 2012

\section{Results of Research}

Prediction of Coping (ESAN) Based on Coping (ACS), Stress (IIEC), and Maladjustment (BASC)

The results of the four linear regression analyses with coping strategies as dependent variables are given in Table 1 and reveal the following: In accordance with the situation-specific approach adopted in this paper, the significant predictors of each factorial strategy -active solution, unproductive coping, avoidance and emotion- vary according to each situation (S1-S4). Therefore, the significant predictors of the active solution factor were as follows: a) ACS1 in the "going to the doctor" (S2) situation, and in the "problems with school grades" (S3) situation; b) ACS2 in all 4 situations; c) ACS3 and DESC in the "problems with peers" (S4) situation; d) APE in the S1, S2, and S4; and e) ISE in the "problems with parents" (S1) situation. The significant predictors of the unproductive coping factor were as follows: a) IIEC (daily stress) in S2 and S3; b) ACS1 in S3 and S4; c) ACS3 in S2, S3 and S4; and d) DESC in S2, S3 and S4. The significant predictors of the avoidance factor were as follows: a) IIEC in S4; b) ACS2 in S2 and S4; and c) DESC in S3 and S4. Lastly, the significant predictors of the emotion factor were as follows: a) ACS1 in S4; b) ACS2 in S1 and S3; c) ACS3 in S2; d) APE and ISE in S1.

Table 1. Regression coefficients $(\beta), R$ squared $\left(R^{2}\right)$ and effect size $\left(f^{2}\right)$ in each ESAN factor.

\begin{tabular}{|c|c|c|c|c|c|c|c|c|}
\hline & \multicolumn{2}{|c|}{ s1 } & \multicolumn{2}{|c|}{ S2 } & \multicolumn{2}{|c|}{ S3 } & \multicolumn{2}{|c|}{ S4 } \\
\hline & $\beta$ & $\mathrm{t}$ & $\beta$ & $t$ & $\beta$ & $\mathrm{t}$ & $\beta$ & $\mathrm{t}$ \\
\hline \multicolumn{9}{|c|}{ Active Solution } \\
\hline IIEC & 0.07 & 1.14 & 0.03 & 0.49 & 0.01 & 0.18 & -0.09 & -1.41 \\
\hline ACS_1 & -0.04 & -0.68 & $0.17^{* *}$ & 2.91 & $0.24^{* *}$ & 4.19 & 0.06 & 1.05 \\
\hline ACS_2 & $0.22^{* *}$ & 3.96 & $0.20^{* *}$ & 3.62 & $0.15^{\star *}$ & 2.72 & $0.25^{\star *}$ & 4.73 \\
\hline ACS_3 & 0.02 & 0.47 & 0.04 & 0.76 & -0.01 & -0.11 & $-0.13^{*}$ & -2.50 \\
\hline DESC & -0.11 & -1.93 & 0.02 & 0.34 & -0.08 & -1.40 & $-0.13^{*}$ & -2.29 \\
\hline $\mathrm{DCL}$ & -0.14 & -1.41 & -0.14 & -1.48 & 0.09 & 1.00 & 0.05 & 0.58 \\
\hline APE & $0.50^{* *}$ & 5.17 & $0.21^{*}$ & 2.14 & 0.09 & 0.99 & $0.22^{*}$ & 2.29 \\
\hline ISE & $0.51^{* *}$ & 3.70 & 0.16 & 1.13 & 0.03 & 0.18 & 0.16 & 1.22 \\
\hline $\mathrm{R} 2$ & \multicolumn{2}{|c|}{0.17} & \multicolumn{2}{|c|}{0.14} & \multicolumn{2}{|c|}{0.16} & \multicolumn{2}{|c|}{0.22} \\
\hline $\mathrm{f} 2$ & \multicolumn{2}{|c|}{0.20} & \multicolumn{2}{|c|}{0.16} & \multicolumn{2}{|c|}{0.19} & \multicolumn{2}{|c|}{0.26} \\
\hline \multicolumn{9}{|c|}{ Unproductive coping } \\
\hline IIEC & -0.09 & -1.31 & $0.18^{* *}$ & 2.72 & $0.20^{* *}$ & 3.05 & 0.04 & 0.56 \\
\hline ACS_1 & 0.11 & 1.90 & -0.08 & -1.50 & $-0.12^{*}$ & -2.19 & $0.21^{* *}$ & -3.70 \\
\hline ACS_2 & -0.01 & -0.21 & 0.08 & 1.54 & 0.07 & 1.28 & 0.09 & 1.63 \\
\hline ACS_3 & 0.04 & 0.68 & $0.12^{*}$ & 2.16 & $0.13^{*}$ & 2.49 & $0.29^{* *}$ & 5.45 \\
\hline DESC & -0.06 & -1.04 & $0.11^{*}$ & 1.97 & $0.23^{* *}$ & 4.19 & $0.15^{\star *}$ & 2.62 \\
\hline $\mathrm{DCL}$ & -0.01 & -0.13 & 0.12 & 1.29 & 0.02 & 0.19 & -0.06 & -0.64 \\
\hline APE & 0.12 & 1.15 & -0.05 & -0.55 & 0.02 & 0.17 & 0.10 & 1.05 \\
\hline ISE & 0.13 & 0.90 & -0.08 & -0.55 & 0.01 & 0.11 & 0.15 & 1.09 \\
\hline $\mathrm{R} 2$ & \multicolumn{2}{|c|}{0.04} & \multicolumn{2}{|c|}{0.15} & \multicolumn{2}{|c|}{0.19} & \multicolumn{2}{|c|}{0.14} \\
\hline f2 & \multicolumn{2}{|c|}{0.05} & \multicolumn{2}{|c|}{0.17} & \multicolumn{2}{|c|}{0.24} & \multicolumn{2}{|c|}{0.17} \\
\hline
\end{tabular}




\begin{tabular}{|c|c|c|c|c|c|c|c|c|}
\hline & \multicolumn{2}{|c|}{ S1 } & \multicolumn{2}{|c|}{ S2 } & \multicolumn{2}{|c|}{ S3 } & \multicolumn{2}{|c|}{ S4 } \\
\hline & $\beta$ & $\mathrm{t}$ & $\beta$ & $\mathrm{t}$ & $\beta$ & $t$ & $\beta$ & $t$ \\
\hline \multicolumn{9}{|c|}{ Avoidance } \\
\hline IIEC & -0.05 & -0.79 & 0.08 & 1.19 & 0.02 & 0.35 & -0.05 & -0.73 \\
\hline ACS_1 & -0.08 & -1.29 & 0.06 & 1.09 & 0.09 & 1.54 & $0.20^{* *}$ & 3.48 \\
\hline ACS_2 & $0.12^{*}$ & 2.04 & 0.10 & 1.83 & $0.28^{* *}$ & 4.92 & 0.11 & 1.86 \\
\hline ACS_3 & 0.06 & 1.14 & $0.17^{* *}$ & 3.06 & -0.01 & -0.16 & 0.07 & 1.23 \\
\hline DESC & -0.04 & -0.70 & 0.02 & 0.42 & -0.07 & -1.30 & -0.04 & -0.74 \\
\hline $\mathrm{DCL}$ & -0.07 & -0.69 & 0.04 & 0.37 & -0.00 & -0.04 & 0.05 & 0.51 \\
\hline APE & $0.37^{* *}$ & 3.71 & 0.09 & 0.95 & 0.08 & 0.83 & 0.02 & 0.19 \\
\hline ISE & $0.45^{\star *}$ & 3.15 & 0.09 & 0.62 & 0.04 & 0.27 & -0.05 & -0.35 \\
\hline $\mathrm{R} 2$ & \multicolumn{2}{|c|}{0.08} & \multicolumn{2}{|c|}{0.11} & \multicolumn{2}{|c|}{0.13} & \multicolumn{2}{|c|}{0.11} \\
\hline f2 & \multicolumn{2}{|c|}{0.09} & \multicolumn{2}{|c|}{0.12} & \multicolumn{2}{|c|}{0.15} & \multicolumn{2}{|c|}{0.13} \\
\hline \multicolumn{9}{|c|}{ Emotion } \\
\hline IIEC & 0.11 & 1.56 & 0.03 & 0.47 & $0.26^{* *}$ & 4.00 & 0.11 & 1.57 \\
\hline ACS_1 & -0.02 & -0.29 & 0.07 & 1.18 & -0.04 & -0.75 & 0.06 & 1.08 \\
\hline ACS_2 & -0.06 & -0.99 & $0.15^{\star \star}$ & 2.62 & 0.01 & 0.28 & $-0.12^{*}$ & -2.03 \\
\hline ACS_3 & 0.06 & 1.08 & 0.07 & 1.25 & 0.02 & 0.38 & 0.09 & 1.67 \\
\hline DESC & 0.09 & 1.61 & 0.06 & 0.92 & $0.24^{* *}$ & 4.42 & $0.17^{* *}$ & 2.89 \\
\hline $\mathrm{DCL}$ & 0.16 & 1.62 & -0.02 & -0.16 & -0.15 & -1.59 & -0.04 & -0.42 \\
\hline APE & -0.06 & -0.63 & 0.08 & 0.76 & -0.08 & -0.84 & 0.02 & 0.16 \\
\hline ISE & -0.09 & -0.66 & 0.07 & 0.50 & -0.00 & -0.02 & -0.03 & -0.21 \\
\hline R2 & \multicolumn{2}{|c|}{0.08} & \multicolumn{2}{|c|}{0.06} & \multicolumn{2}{|c|}{0.18} & \multicolumn{2}{|c|}{0.06} \\
\hline f2 & \multicolumn{2}{|c|}{0.09} & \multicolumn{2}{|c|}{0.07} & \multicolumn{2}{|c|}{0.22} & \multicolumn{2}{|c|}{0.06} \\
\hline
\end{tabular}

Note: S1 = Problem with parents; S2 = Going to the doctor; S3 = Problem with school grades; S4 = Problem with peers; IIEC = Children Inventory of Daily Stressors; ACS_1 = Coping focused on the problem; ACS_2=Coping in relation to others; ACS_3=Unproductive coping; $D E S C=$ School maladjustment; $D C L=$ Clinical maladjustment; $A P E=$ Personal adjustment; ISE = Emotional Symptoms Index. The effect size $f^{2}=R^{2} /\left(1-R^{2}\right)$, by convention $f^{2}$ effect sizes of $0.02,0.15$, and 0.35 are considered small, medium, and large, respectively (Cohen, 1992); ${ }^{*} p<0.05 ;{ }^{* *} p<0.01$.

\section{Discussion}

A situation-specific assessment such as the one carried out in this study, is considered as the most effective to assess coping strategies, given that these strategies emerge in a contextualised way and are different depending on each problem or situation (Cano, Garcia, \& Rodriguez, 2004; Grant et al., 2006; Halama \& Bakosova, 2009). In this line of thought, an instrument (ESAN) checks coping strategies with daily stressors in four situations or problems arisen from daily life during childhood and adolescence. This instrument offers adequate validity and reliability, as well as a structure that allows the assessment of coping strategies in four different childhood situations: active solution, unproductive coping, avoidance and emotion.

The active solution factor includes the following strategies: active solution, positive reassessment, information search and social support. From these, the first three strategies belong to the so-called Problem-Solving field (Griffith, Dubow, \& Ippolito, 2000; Trianes, 1988), whereas the fourth strategy accounts for a classic strategy due to its balancing effect on children's development (Maton, 1988).

The unproductive coping factor consists of strategies of aggressive behaviour and problem- 
hiding. Aggressive behaviour is considered fairly among the unproductive coping strategies, as it is usually a way to cope with interpersonal conflicts during childhood - more rarely during adolescence, and is often associated with unresolved interpersonal conflicts (Trianes, Muñoz, \& Jimenez, 1996). From mid-childhood onwards, non-socialised interpersonal aggressiveness can predict future adaptation problems even during adulthood (Burgess, Wojslawowicz, Rubin, Rose-Krasnor, $\&$ Booth-LaForce, 2006). This is why the use of aggressive strategies to cope with problems with peers, teachers or relatives is to say the very least unproductive, given that the criteria provided by these social agents regard aggressiveness as an inadequate behaviour within social interaction (Seiffge-Krenke, 2000).

The avoidance factor can either be of a cognitive nature or of a behavioural nature. Both strategies have been separately considered in some published categorisations (Ayers, Sandler, West, \& Roosa, 1996). There are reasons enough for separating them as well as for placing them under a unique factor. These reasons are based on the fact that both strategies do not involve coping directly with the problem but rather attempting to avoid or postpone it. On the other hand, whereas behavioural avoidance is evident, cognitive avoidance is not, and it can become a child or adolescent's last resort when behavioural avoidance is not possible; for instance, during a medical check or when suffering invasive medical procedures in hospitals (Altshuler, Genevro, Ruble, \& Bornstein, 1995).

Finally, the emotion factor consists of strategies of emotion and passivity. It is not surprising for passivity - which accounts for a classic strategy - to be associated with emotional strategies when such strategies involve crying, sadness or melancholy. These strategies can be compared with other categorisations described in the literature (Cano et al., 2004; Stone, Greenberg, Kennedy-Moore, \& Newman, 1991).

It has been obtained that the ACS variables have contributed the most to predicting the ESAN factors, by showing a high association between both assessment measures within the coping field. Additionally, variables from the stress test (IIEC) and from the BASC also offer significant associations which report indicators of external validity that are acceptable for the ESAN.

However, in relation to the situation-specific approach, it can be observed that the coping in relation to others (ACS2) has proven to play an important role when predicting only the active solution factor in the four situations. On the contrary, it does not play any role when predicting unproductive coping, whereas its score is significant when predicting avoidance only in "going to the doctor" (S2) and in "problems with peers" (S4). Likewise, when it comes to predict emotion, its score is only significant in relation to "problems with parents" (S1) and "problems with school grades" (S3). Focused on the problem coping (ACS1) accounts for a key factor when predicting the active solution strategy, which is not surprising provided that both share a focusing on solving the problem approach. The unproductive coping (ACS3) predicts the same-named factor in three situations: peers, school grades and doctor; except for the "problems with parents", where it does not play any role. Neither has it participated in the prediction of other ESAN factors, except for the prediction of emotion in the "going to the doctor" situation, which is understandable given that crying in the "going to the doctor" situation does not seem to be productive at all. The IIEC variable (daily stress in children) predicts unproductive coping, which refers to stress not being helpful when successfully coping with "going to the doctor" or "bringing home poor school grades" situations. It does also predict another strategy of a doubtful efficacy: Avoidance in the "bringing home poor school grades" situation. The literature shows coherent correlations between stress and coping strategies (Bagdi \& Pfister, 2006; Halama \& Bakosova, 2009). Such correlations are positive in relation to unproductive and dysfunctional coping, and negative in relation to productive and functional coping.

The practical application of the above results is evident, since teaching stressed and non-stressed children positive coping strategies will be useful in order to promote their optimal development. From the BASC variables, school maladaptation is the most active one, playing an important role in the prediction of unproductive coping in "problems with school grades" and "problems with peers". It also predicts avoidance strategies significantly in relation to "problems with school grades" and "problems with peers". Another variable from the same test, emotional symptoms, helps to predict the active solution strategy and also predicts the emotion strategy in the "problems with parents" situation. The demonstration of emotion on the part of a son or daughter can be thought to help solve a conflictive situation in the family. At last, personal adjustment, predicts significantly the 
active solution strategy, in the "problems with parents", "going to the doctor" and "problems with school grades" situations. It also predicts emotion in the "problems with parents" situation, which contributes to shaping a productive role for emotional manifestation in interpersonal situations, a result corroborated by other studies, too (Burgess et al., 2006; Donaldson, Prinstein, Danovsky, \& Spirito, 2000; Frydenberg \& Lewis, 2004; Griffith et al., 2000). At last, it is worth stressing the null and void role placed by clinical maladaptation, in spite of the fact that the correlation of this variable with unproductive coping and with avoidance strategies is mentioned in further studies (GomezFraguela et al., 2006).

A possible limitation of this research has been the use of self-reports, excluding the participation of further sources. With future work, we have thought of the possibility of introducing the analysis of family data in the model with parents contributing their own views. However, it is widely accepted that children themselves should provide their own assessment, given that their perceptions are more relevant than other sources' to explain the origin of psychopathologies or quality of life.

\section{Conclusions}

In summary, the information that is presented in this study can be helpful for school counsellors to assess their students, both in general and in relation to specific problems. It can also be useful to clinical psychologists searching for a complete diagnosis of adaptation or adjustment, as it allows comparisons to be made with other non-clinical samples. All of this with the purpose of contributing, in a precise and effective way, to the assessment and intervention of coping with daily stress in children, by helping to design better treatments.

The findings of the present research study are believed to contribute to the development of more effective preventive actions and psycho-educational interventions in the area of children's coping with daily stress. The above implications lead to an approach, which revolves around the prevention of school-children's everyday stress, based on programmes and educational activities that are aimed at dealing with stress whilst also using more productive and effective coping strategies.

\section{Acknowledgements}

This study was funded by the Dirección General de Investigación (General Research Design). Spanish Ministry of Education and Science. (Ref. SEJ2007-61447) (2007-2010).

\section{References}

Altshuler, J. L., Genevro, J. L. Ruble, D. N., \& Bornstein, M. H. (1995). Children's knowledge and use of coping strategies during hospitalization for elective surgery. Journal of Applied Developmental Psychology, 16, 53-76.

Ayers, T. S., Sandler, I. N., West, S. G., \& Roosa, M. W. (1996). A dispositional and situational assessment of children's coping: testing alternative models of coping. Journal of Personality, 64, 923-958.

Bagdi, A., \& Pfister, I. (2006). Childhood stressors and coping actions: A comparison of children: A parents' perspective. Child \& Youth Care Forum, 35, 21-40.

Burgess, K. B., Wojslawowicz, J.C., Rubin, K. H., Rose-Krasnor, L. R., \& Booth-LaForce, C. (2006). Social information processing and coping styles of shy/withdrawn and aggressive children: Does friendship matter? Child Development, 77, 371-383.

Cano, F. J., García, J., \& Rodríguez, L. (2004). Contextual assessment of stress coping strategies. IV European Conference on Psychological Assessment. EAPA 2004.

Carretero-Dios, H., \& Pérez, C. (2005). Normas para el desarrollo y revisión de estudios instrumentales. International Journal of Clinical and Health Psychology, 5, 521-551.

Claes, L., Witteman, C., \& Van den Bercken, J. (2009). Situational variability of experiential and rational information-processing styles in stressful situations. European Journal of Psychological Assessment, $25,107-114$.

Compas, B. E., Connor-Smith, J. K., Saltzman, H., Thomsen, A. H., \& Wadsworth M. E. (2001). Coping 
OF PSYCHOLOGY

IN THE $21^{\text {st }}$ CENTURY Volume 3, 2012

74

with stress during childhood and adolescence: Problems progress and potential in theory and research. Psychological Bulletin, 127, 87-127.

Connor-Smith, J. K., Compas, B. E., Wadsworth, M. E., Thomsen, A. H., \& Saltzman, H. (2000). Responses to stress in adolescence: Measurement of coping and involuntary stress responses. Journal of Consulting and Clinical Psychology, 68, 976-992.

Donaldson, D., Prinstein, M. J., Danovsky, M., \& Spirito, A. (2000). Patters of children's coping with life stress: Implications for clinicians. American Journal of Orthopsychiatry, 70, 351-359.

Frydenberg, E., \& Lewis, R. (1993). The adolescent coping scale: Practitioners manual. Melbourne: Australian Council for Educational Research.

Frydenberg, E., \& Lewis, R. (1996). A replication study of the structure of the Adolescent Coping Scale: Multiple forms and applications of a self-report inventory in a counselling and research context. European Journal of Educational Psychological Assessment, 12, 224-235.

Frydenberg, E., \& Lewis, R. (2004). Adolescents least able to cope: How do they respond to their stresses? British Journal of Guidance \& Counselling, 32, 25-37.

Folkman, S., \& Moskowitz, J. T. (2004). Coping: pitfalls and promise. Annual Review of Psychology, 55, 745-774.

Gomez-Fraguela, J. A., Luengo, A., Romero, E. Villar, P., \& Sobral, J. (2006). Estrategias de afrontamiento en el inicio de la adolescencia y su relación con el consumo de drogas y la conducta problemática. International Journal of Clinical and Health Psychology, 6, 581-597.

Gonzalez, J., Fernandez, S., Perez, E., \& Santamaria, P. (2004). Adaptación española de sistema de evaluación de la conducta en niños y adolescentes: BASC. Madrid: TEA Ediciones.

Grant, K. E., Compas, B. E., Thurm, A. E., McMahon, S. D., Gipson, P. Y., Campbell, A. J. et al. (2006). Stressors and child and adolescent psychopathology: Evidence of moderating and mediating effects. Clinical Psychology Review, 26, 257-283.

Griffith, M. A., Dubow, E., \& Ippolito, M. F. (2000). Developmental and cross-situational differences in adolescents' coping strategies. Journal of Youth and Adolescence, 29, 183-204.

Halama, P., \& Bakosova, K. (2009). Meaning in life as a moderator of the relationship between perceived stress and coping. Studia Psychologica, 51, 143-148.

Hampel, P., \& Petermann, F. (2006). Perceived stress, coping, and adjustment in adolescents. Journal of Adolescent Health, 38, 409-415.

Keane, S. P., \& Calkins, S. D. (2004). Predicting kindergarten peer social status from toddler and preschool problem. Behaviour. Journal of Abnormal Child Psychology, 32, 409-423.

Krane, W. R., \& Slaney, K. L. (2005). A general introduction to the common factor model. In Maydeu-Olivares \& J. J. McArdle (Eds.), Contemporary Psychometrics. A festschrift for Roderick P. McDonald (pp. 125151). Mahwah, NJ: Lawrence Erlbaum Associates.

Lazarus, R. S., \& Folkman, R. S. (1984). Stress appraisal and coping. New York: Springer Publishing Company (Spanish translation: Estrés y procesos cognitivos, Barcelona, Martínez Roca, 1986).

Maton, K. L. (1988). Social support, organizational characteristics, psychological well-being and group appraisal in three self help group populations. American Journal of Community Psychology, 16, 53-78.

Penley, J., Tomaka, J., \& Wiebe, J. (2002). The association of coping to physical and psychological elath outcomes: A meta-analytic review. Journal of Behavioral Medicine, 25, 551-603.

Reynolds, C., \& Kamphaus, R. W. (1992). Behaviour assessment system for children-BASC. Circle Pines: American Guidance Service.

Salkovskis, P. M., \& Campbell, P. (1994). Thought suppression induces intrusion in naturally occurring negative intrusive thoughts. Behaviour Research and Therapy, 32, 1-8.

Sandín, B. (2003). El estrés: un análisis basado en el papel de los factores sociales. [The stress: a critical overview focused on the relevance of social factors]. Revista Internacional de Psicología Clínica y de la Salud, 3, 141-157.

Santed, M. A., Sandín, B., Chorot, P., \& Olmedo, M. (2000). Predicción de la sintomatología somática a partir del estrés diario: Un estudio prospectivo controlando el efecto del neuroticismo. [Predicting somatic symptomatology from daily stress: a prospective study controlling the effect of the neurotic personality]. Revista de Psicopatología y Psicología Clínica, 5, 165-178. 
Santed, M. A., Sandín, B., Chorot, P. \& Olmedo, M. (2001). Predicción de la sintomatología somática a partir Volume 3, 2012 del estrés diario y de los síntomas previos: Un estudio prospectivo. [Predicting somatic symptomatology from daily stress and previous symptoms: A prospective study]. Ansiedad y Estrés, 6, 317-329.

Seiffge-Krenke, I. (2000). Causal links between stressful events, coping style and adolescent symptomatology. Journal of Adolescence, 23, 675-691.

Seiffge-Krenke, L., \& Klessinger, N. (2000). Long-term effects of avoidant coping on adolescents' depressive symptoms. Journal of Youth and Adolescence, 29, 617-630.

Spirito, A., Stark, L., Gil, K. M., \& Tyc, V. (1995). Coping with everyday and disease-related stressors by chronically ill children and adolescents. Journal of the American Academy of Child and Adolescent Psychiatry, 34, 283-290.

Spirito, A., Stark, L., \& Williams, C. (1988). Development of a brief checklist to assess coping in pediatric patients. Journal of Pediatric Psychology, 13, 555-574.

Stern, M., \& Zevron, M. A. (1990). Stress, coping and family environment: The adolescent's response to naturally occurring stressors. Journal of Adolescent Research, 5, 290-305.

Stone, A. A., Greenberg, M., Kennedy-Moore, E., \& Newman, M. G. (1991). Self-report, situation-specific coping questionnaires: What are they measuring? Journal of Personality and Social Psychology, 61, 648-658.

Tein, J. Y., Sandler, I. N., \& Zautra, A. J. (2000). Stressful life events, psychological distress, coping, and parenting of divorced mothers: A longitudinal study. Journal of Family Psychology, 14, 27-41.

Trianes, M. V. (1988). Enseñanza de competencia social en la escuela: Breve revisión crítica de los trabajos de Spivack y Shure. [Social competence teaching in school: Brief critical review of the studies of Spivack and Shure]. Anuario de la UNED de Málaga, II, 163-188.

Trianes, M.V., Blanca, M. J., Fernández, F. J., Escobar, M., Maldonado, E., \& Muñoz, A. (2009). Estudio psicométrico inicial del Inventario Infantil de Estresores Cotidianos (IIEC). [A preliminary psychometric study of the Children Daily Stressors Inventory]. Psicothema, 21, 598-603.

Trianes, M. V., Muñoz, A., \& Jiménez, M. (1996). Importancia de la situación en la solución a problemas interpersonales hipotéticos según la edad. [Relevance of the situation in hypothetical interpersonal problems solutions according to age]. Infancia y Aprendizaje, 75, 107-123.

Urzua, A., \& Jarne, A. (2008). Calidad de vida y estilos de afrontamiento en personas con patologías crónicas. [Quality of life and coping styles in people with chronic pathologies]. Interamerican Journal of Psychology, 42, 151-160.

Advised by Vincentas Lamanauskas, University of Siauliai, Lithuania

Received: April 26, 2012

Accepted: June 11, 2012

Francisco Manuel Morales Rodríguez
PhD in Psychology and Bachelor of Labour, Associate Professor (Doctor), Department of Psychology and Education, School of Psychology, University of Malaga, Campus de Teatinos s / n, 29071, Malaga, Spain.

E-mail: framorrod@uma.es

Website: http://webdeptos.uma.es/psicoev/ 